\title{
Histopathological evaluation of medial patellar ligament and radiographic evaluation of the stifle joint of upward fixation of patella affected bovines
}

\author{
M. Naveen ${ }^{1}$, D. Dilip Kumar ${ }^{1}$, B. V. Shivaprakash ${ }^{1}$, S. M. Usturge ${ }^{1}$ and Ashok Pawar ${ }^{2}$ \\ 1. Department of Surgery and Radiology, Veterinary College, Karnataka Veterinary Animal and Fisheries Sciences \\ University, Nandinagar, Bidar-585 401, Karnataka, India; 2. Department of Anatomy and Histology, Veterinary College, \\ Karnataka Veterinary Animal and Fisheries Sciences University, Nandinagar, Bidar-585 401, Karnataka, India \\ Corresponding author: M. Naveen, email: naveencspvet@gmail.com \\ Received: 22-01-2014, Revised: 01-03-2014, Accepted: 05-03-2014, Published online: 03-04-2014
}

doi: 10.14202/vetworld.2014.200-204 How to cite this article: Naveen M, Dilip Kumar D, Shivaprakash BV, Usturge SM and Pawar A (2014) Histopathological evaluation of medial patellar ligament and radiographic evaluation of the stifle joint of upward fixation of patella affected bovines, Veterinary World 7(4): 200-204.

\begin{abstract}
Aim: To evaluate the medial patellar ligament by histopathology and stifle joint by radiography of upward fixation of patella affected bovines.

Materials and Methods: Present study was conducted on 24 clinical cases of bovines. Out of twenty four clinical cases of upward fixation of patella, twelve were buffaloes, six were cows and remaining six were bullocks. Histopathological evaluation of medial patellar ligament from the affected animals and radiographic evaluation of stifle joint were done as per standard procedure.

Results: Histopathological observations were made as follows. Nuclei of the fibroblasts were oval shaped and hypertrophied, as compared to thin, elongated normal nuclei. There was an excessive proliferation of fibrous connective tissue. There was a presence of mononuclear cells and fibrin exudates in the surrounding loose connective tissue of the ligament and medial coat of the blood vessels of medial patellar ligament was thickened. Plain radiographs that were taken in the medio-lateral view did not reveal any evidence of upward or dorsal deviation of patella in relation to the femoral condyle.
\end{abstract}

Conclusions: Histopathological evaluation of the medial patellar ligaments of upward fixation of patella affected bovines showed various pathological changes, while radiography of the stifle joint did not confirm the condition.

Keywords: bovines, patella, desmotomy, ligament, histopathology, radiography.

\section{I ntroduction}

Upward fixation of patella is one of the most commonly seen condition in cattle and buffalo $[1,2,3]$. It is a multifactorial disease [2,3,4]. Sporadic occurrences are seen in dairy cattle and it is reported to be quite common with draft bullocks in India [5,6]. Incidence is quite higher in buffaloes compared to cattle $[7,8]$. Among the patellar ligaments, middle patellar ligament is thick and strong as compared to medial and lateral patellar ligaments $[9,10]$. In the present study, medial patellar ligament of the affected cattle and buffaloes was subjected to histopathological study. Plain radiograph of the stifle joint was taken. Whenever lameness occurs due to medial patellar desmotomy, consideration should be given to both radiography of the stifle joint and ultrasonagraphy of the middle patellar ligament [11]. Medial patellar ligament is thin, flattened like ribbon and weaker than middle and lateral patellar ligament $[3,12]$. From the clinical point of view the stifle joint is very important; it includes the femeropatellar and

Copyright: The authors. This article is an open access article licensed under the terms of the Creative Commons Attribution License (http://creativecommons.org/licenses/by/2.0) which permits unrestricted use, distribution and reproduction in any medium, provided the work is properly cited. femerotibial joints [13].

The present study was aimed to evaluate the medial patellar ligament by histopathology and stifle joint by radiography of upward fixation of patella affected bovines.

\section{Materials and Methods}

Ethical approval: Not necessary. All the clinical cases under this research were treated and examined as per standard treatment and examination procedure.

Animals: Twenty four clinical cases of bovines affected with upward fixation of patella were considered for the study. Twelve out of twenty four animals were buffaloes, six were cows and remaining six were bullocks. These animals were randomly divided into four groups with six animals in each group (Table-1). Medial patellar ligament of the affected bovines was subjected to histopathology and the radiographs of their stifle joint were taken.

Histology: Excised piece of medial patellar ligament was collected in neutral buffered formalin. The tissues were processed as per routine paraffin and embedding technique. The paraffin sections were cut to a size of 35 microns thickness. The slides were stained with 
Table-1: Detailed technical layout of the study.

\begin{tabular}{clcl}
\hline Sr. No. & Group & Number of animals & Surgical techniques evaluated \\
\hline 1. & I (Buffaloes) & 06 & Recumbent, open method of medial patellar desmotomy. \\
2. & II (Cows) & 06 & Recumbent, closed method of medial patellar desmotomy. \\
3. & III (Bullocks) & 06 & Standing, open method of medial patellar desmotomy. \\
4. & IV (Buffaloes) & 06 & Standing, closed method of medial patellar desmotomy. \\
\hline
\end{tabular}

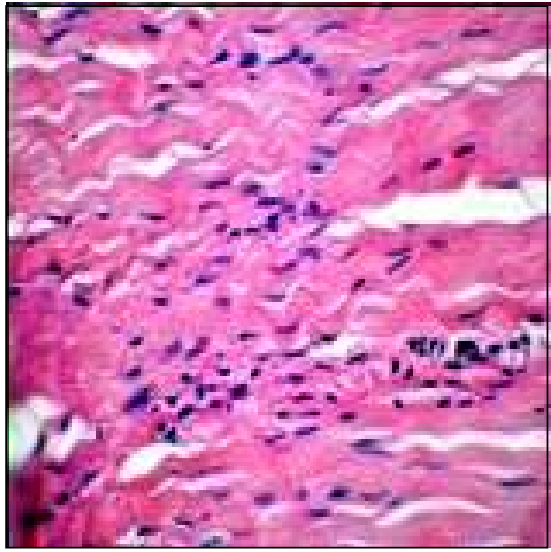

Figure-1: Photomicrograph of a medial patellar ligament from the affected animal showing oval shaped and hypertrophied nucleus of the fibroblasts. ( $40 \times-\mathrm{H}$ and $\mathrm{E}$ )

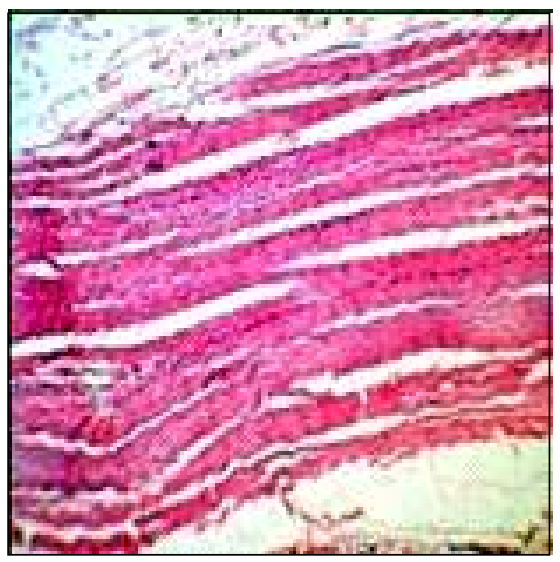

Figure-4: Photomicrograph of a medial patellar ligament from the normal animal showing thin and elongated nuclei and normal orientation of the collagen bundles. ( $10 \times-\mathrm{H}$ and $\mathrm{E})$

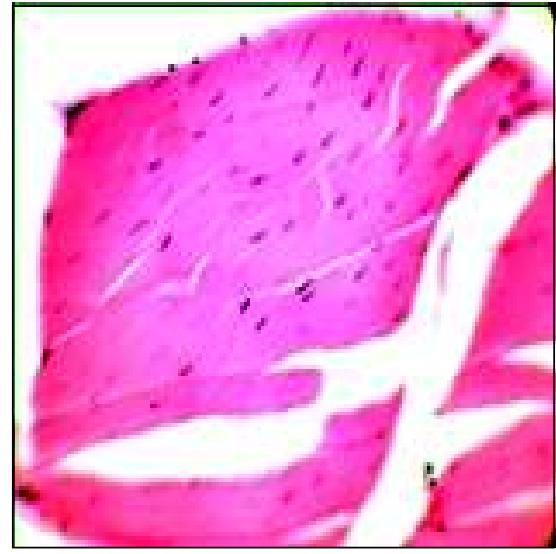

Figure-2: Photomicrograph of a medial patellar ligament from the normal animal showing thin and elongated nuclei. ( $40 \times-H$ and $E$ )

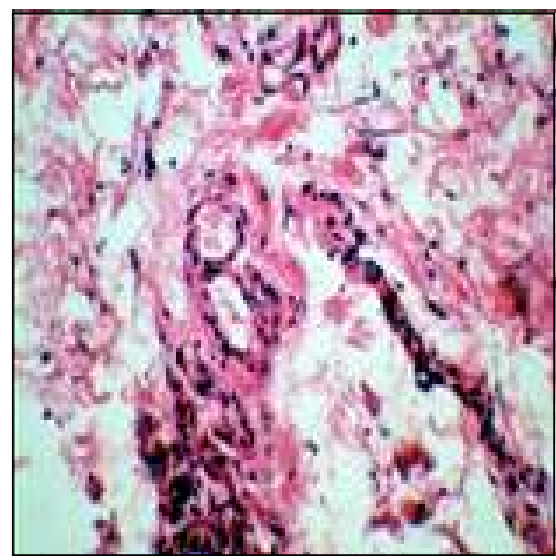

Figure-5: Photomicrograph of a medial patellar ligament from the affected animal showing presence of mononuclear cells and fibrin exudate in the surrounding loose connective tissue of the ligament. ( $40 \times-\mathrm{H}$ and $\mathrm{E}$ )

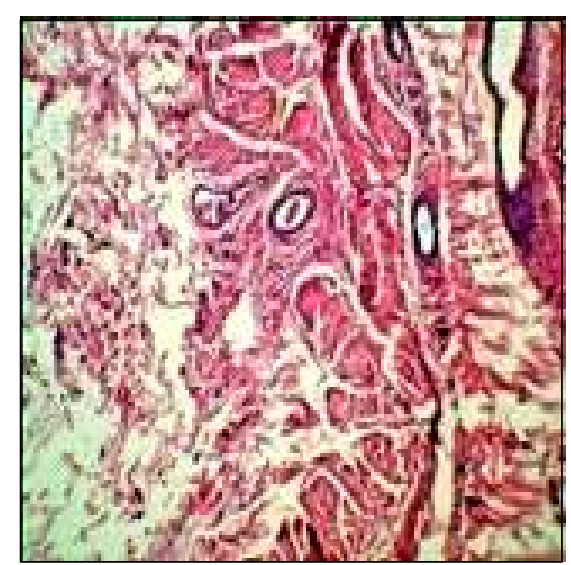

Figure-3: Photomicrograph of a medial patellar ligament from the affected animal showing excessive proliferation of fibrous connective tissue. (10x-H and $\mathrm{E}$ )

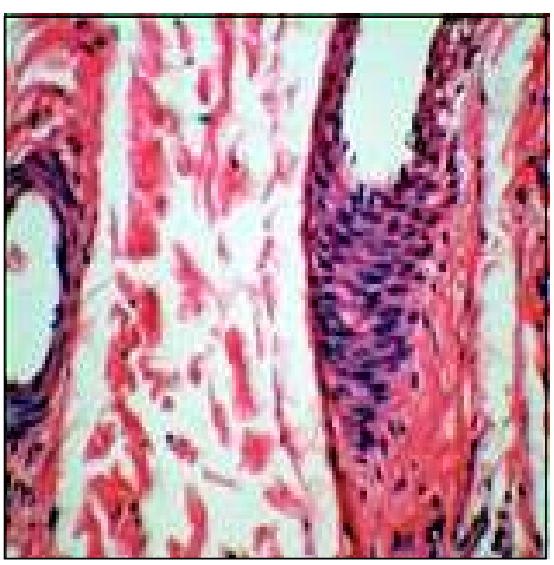

Figure-6: Photomicrograph of a medial patellar ligament from the affected animal showing thickening of medial coat of the blood vessels. $(40 \times-\mathrm{H}$ and E)
Haematoxylin and Eosin for histopathological studies [14]. Lateral radiograph of stifle joint of the affected animal was taken in $500 \mathrm{~mA} \mathrm{X}$ - ray machine in a 12 "x15" films for diagnosing upward fixation of patella in bovines. Exposure factors used were 14 to 18 $\mathrm{mAs}$ and 68 to $75 \mathrm{kVp}$ at $90 \mathrm{~cm}$ FFD in a grid cassette [15].

\section{Results and Discussion}

Histopathological observations were made as follows;

Nuclei of the fibroblasts were oval shaped and hypertrophied (Figure-1) as compared to thin, elongated normal nuclei (Figures-2 and 4). There was an excessive proliferation of fibrous connective tissue (Figure-3). There was a presence of mononuclear cells and fibrin exudates in the surrounding loose connective tissue of the ligament (Figure-5) and medial coat of the blood vessels of medial patellar ligament was thickened (Figure-6).

Present study results are in agreement with several earlier studies. There was a mononuclear cell proliferation in the medial patellar ligament of the affected bullocks [16]. Histopathological study of medial patellar ligaments showed the hypertrophy of the medial coat of the blood vessels and increased fibrous tissue in the whole ligament [17]. Histopathology of the medial patellar ligaments of the affected bovines showed, hypertrophied and oval nuclei of fibroblasts, medial coat of the blood vessels was thickened, increased white fibrous connective tissue proliferation, individual fibres of the ligament were 


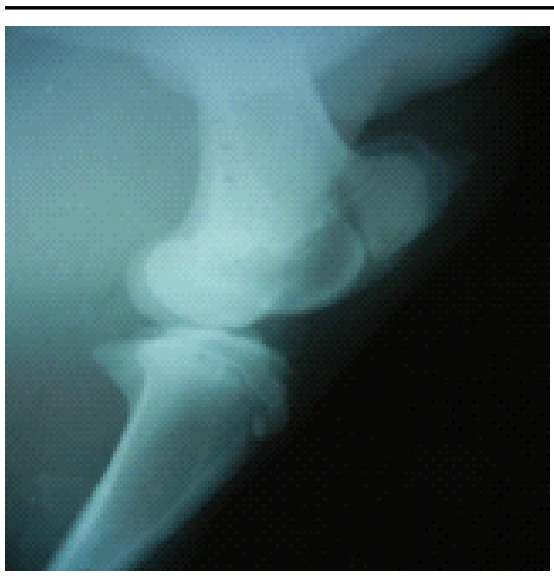

Figure-7: Lateral radiograph of the stifle joint of a buffalo.

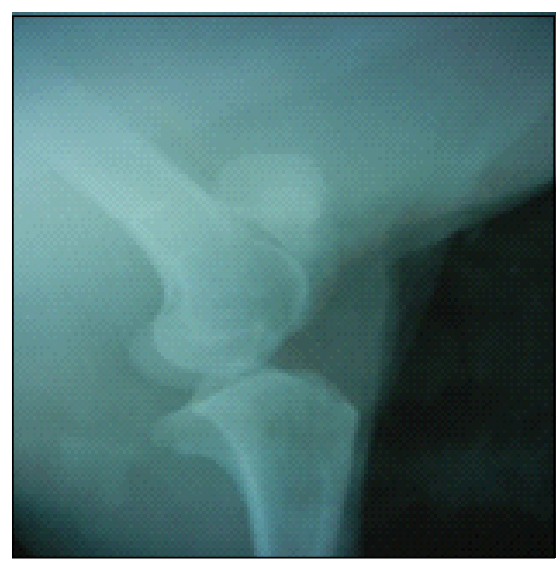

Figure-8: Lateral radiograph of the stifle joint of a cow.

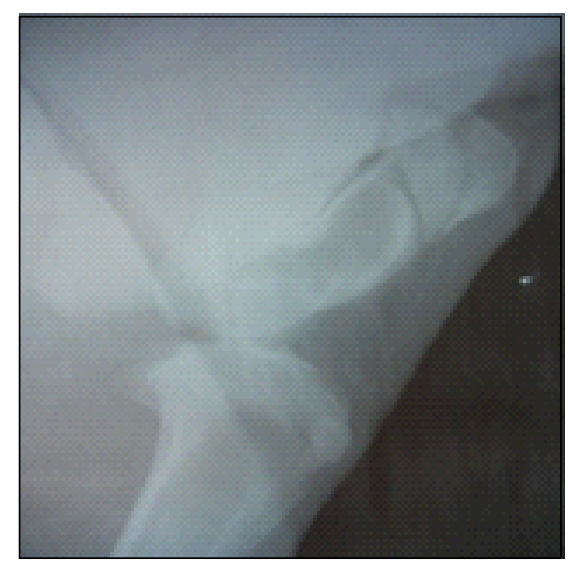

Figure-9: Lateral radiograph of the stifle joint of a bullock. hyalinised and the diameter of the collagen fibre bundle was increased [18]. Under light microscope, histology of the ligament showed fibrocytes interspersed between the extracellular fibres [19].

The degree of fibrous tissue proliferation was more in the bovines that were affected for long period of time. In the group IV, two buffaloes showed the clinical signs after medial patellar desmotomy by standing closed method and histology of the medial patellar ligament of the two buffalo's revealed excessive proliferation of the fibrous connective tissue. This indicated that severe fibrosis of the medial patellar ligament might be the cause for persistent clinical signs of lameness after medial patellar desmotomy in these animals. There were no differences noticed in the histology of the medial patellar ligaments of normal cows, buffaloes and bullocks. But, the only difference noticed in the present study was the degree of fibrous tissue proliferation in the medial patellar ligament of the affected animals. It was more in the medial patellar ligaments of animals affected for long period and lesser in the ligaments of the animals affected for short period of time. Animals of different group in the present study that were presented early to the Teaching Veterinary Clinical Complex, Veterinary College, Bidar did not show clinical signs of lameness after medial patellar desmotomy and that were presented after 6 months of affected ligament showed persistent clinical signs of lameness after medial patellar desmotomy. This was due to severe fibrosis of the medial patellar ligament.

However, following observations were not noticed in the present study;

Histologically medial patellar ligament was distinctly weaker than the middle or the lateral [20]. Medial ligament was strengthened by an accessory fibrocartilage [21]. Longitudinal sections of medial patellar ligaments of 31 bovine animals ( 12 normal and 19 affected) were prepared and the diameter of the collagen fibre bundle was measured and the affected ligaments had the largest diameters when compared to normal ones [22]. On histopathological examinations the saphenous branch of femoral nerve which supplies the medial patellar ligament and joint capsule showed degenerative changes in myelin sheath of the nerve from an affected animal [23]. In the present study, plain radiographs that were taken in the medio-lateral view did not reveal any evidence of upward or dorsal deviation of patella in relation to the femoral condyle (Figure-7, 8 and 9). For taking the radiograph in medio-lateral view, animal was casted to lateral recumbency with the affected hind limb stretched. When the leg is stretched, patella automatically moved dorsally. Hence, we could not specifically point out the dorsal deviation of the patella in a plain radiograph of upward fixation of patella affected animals.

Similar observations were reported by several workers. There was no evidence of dorsal or medial deviation of patella in relation to the femoral condyle in the plain radiographs of stifle joints of upward fixation of patella affected animals [18]. It was not possible to use radiography for the diagnosis of upward fixation of patella [24]. Radiographs of stifle joint of upward fixation of patella affected animals failed to demonstrate any abnormal anatomical disposition of the patella in relation to the femoral condyle [25]. No radiographic sign could be used to confirm the clinical diagnosis of recurrent upward fixation of patella in horses and radiographical examination of the stifle was recommended to exclude other concurrent stifle lesions that might affect the choice of treatment and prognosis [15].

However, the following observations made in the present study were not observed by several earlier studies reported. There was a flattened condition of the inner lip of the trochlea in a radiograph of stifle joint of large animals affected with upward fixation of patella [26]. Roentgenographic examination of stifle joint of the upward fixation of patella affected animals revealed congenital deformity in the stifle joint [27]. There was a defective shape of the trochlea in a radiograph of the stifle joint of upward fixation of patella affected animal [28]. Radiographic examination of the stifle joint of upward fixation of patella affected animals showed the absorption of fat between the straight ligaments and the joint [29]. Radiograph of the stifle joint of upward fixation of patella affected animal indicated fibrosis or osseous proliferation of the stifle joint [30]. Radiographic examination of the stifle joint of upward fixation 
of patella affected animal revealed dry condition of the joint [31]. Plain radiographs of stifle joints could indicate patellar luxation in dogs and are useful to determine the extent of bony deformity and degenerative joint changes [32].

\section{Conclusions}

Histopathology of affected medial patellar ligament showed pathological changes like hypertrophy of the nuclei of fibroblasts and the nuclei were oval shaped, thickening of medial coat of the blood vessels, excessive proliferation of the fibrous connective tissue and presence of mononuclear cells and fibrin exudates in the surrounding loose connective tissue. These indicate that the condition will produce some degenerative changes in the medial patellar ligament of the affected bovines. The different methods of medial patellar desmotomy were successful in complete elimination of the clinical signs of lameness in the affected bovines of different group, when the cases were presented early. The radiography was not useful for diagnosis of upward fixation of patella in bovines.

\section{Authors' contributions}

MN prepared histology slides under the guidance of AP. MN has taken plain radiographs of the stifle joint of the affected bovines under the guidance of DDK, BVS and SMU. All authors participated in draft and revision of manuscript.

\section{Acknowledgements}

The authors acknowledge the facilities and financial support provided for the present study from Karnataka Veterinary Animal and Fisheries Sciences University, Bidar, Karnataka, India.

\section{Competing interests}

The authors declare that they have no competing interests.

\section{References}

1. Dhillon, K. S., Jasmer Singh, B. B. S., Dhaliwal., Rajnish Sharma and Pannu, M. S. (2009) Patellar luxation in buffalo and its treatment. Buffalo Bulletin., 28(4): 168-169.

2. Gangawar, A. K., Naveen Kumar and Sangeeta Devi, Kh. (2010) General Animal Surgery and Anesthesiology. New India Publishing Agency, New Delhi., p169.

3. Uddin, M. M., Reza, S. M., Islam, N. K., Miazi, O. F. and Ahmed, S. S. U. (2009) Surgical anatomical measurements of patellar ligaments for blind method of medial patellar desmotomy of cattle during upward patellar fixation in Bangladesh. Int. J. Morphol. 27(2):311-315.

4. Chumchoung, C. and Chawanit, M. (2009) A surgical treatment of upward fixation of the patellar in American Brahman cow. Journal of Mahanakorn Veterinary Medicine. 4(2): 71-78

5. Ashwood., A. (2009) Stringhalt in cattle. Technical information-general. Australian Brahman Breeders' Association Limited. p11-12.

6. Chandrapuria, V.P., Bhadauria Pragya and Jadoun, Y.S. (2012) Upward Fixation of Patella and its Clinical Management in Large Ruminants. Intas Polivet. 13(2): 259261.

7. Abdalla, H., Abdalla, K., Yosrria, A., Rahman, A., Khaled, A. and Ruwaida, A. (2013) Why the incidence of the upward fixation of thepatella is higher in buffalos than in cattle? European J. Vet. Med.2: 109-142.

8. Mondal, S., Karnam, S. S., Baranwal, A. K., and Das, P. (2013) Medial patellar desmotomy by blind method in large ruminants during upward patellar fixation. Explor. Anim. Med.Res.3(2): 184-185.

9. Mejbah-uddin, M., Salim Reza, M., Nurul Islam, K., Faruk Miazi, O. and Ahmed, S. U. (2009) Surgical Anatomical Measurements of Medial Patellar Ligaments for Blind Method of Medial Patellar Desmotomy of Cattle During Upward patellar Fixation in Bangladesh. Int. J. Morphol. 27(2):311-315.

10. Tyagi, R. P. S. and Jit Singh. (2008) Ruminant Surgery, Edn $9^{\text {th }}$., CBS Publishers and Distributors., New Delhi. p313-317.

11. Kassab, A. and Badawy, A. (2011) Ultrasonagraphic examination of the patellar ligaments before and after medial patellar desmotomy in buffaloes (Bos bubalis). Emir. J. Food Agric. 23 (5): 460-465.

12. Roger, W. B and David Weaver, A. (2011) Color Atlas of Diseases and Disorders of Cattle. Edn $3^{\text {rd }}$. Elsvier Ltd. p130.

13. Abdalla Hifny., Kamal Eldin Hashem Abdalla., Yousria, A., Abdel Rahman., Khaled Aly and Ruwaida Abdelmoaty Elhanbaly. (2012) Morphometric studies on the passive role of menisci in upward fixation of the patella in buffalo and cattle. Vet Sci. Develop., 2: 63.

14. Culling, C. F. (1974) Handbook of Histopathological and Histochemical Techniques. $3^{\text {rd }}$ edition, Butterworth and Co, London.,p193-197.

15. Donald, E. T. (2007) Textbook of Veterinary Diagnostic Radiology, Edn $5^{\text {th }}$., Elsevier, A division of Reed Elsevier India Private Limited, Noida, Uttarpradesh., p362-363.

16. Sahu, N. (1971) Diverse surgical approaches and pathophysiology of bovine upward fixation of patella. M. V. Sc. Thesis. Orissa University of Agriculture and Technology, Bhubaneswar, India.

17. Tyagi, R. P. S., Krishnamurthy, D and Kharole, M. U. (1973) Studies on the histopathology of ligaments in bovine animals affected by upward fixation of the patella. Vet.Rec., 93(13): 362-364.

18. Tyagi, R. P. S. and Krishnamurthy, D. (1976) Upward fixation of patella., publications division, Haryana Agriculture University, Hissar. p1-88.

19. Don, A. S. (2007) Textbook of Veterinary Histology, Edn $1^{\text {st }}$., Saunders Elsevier, Westline Industrial Drive, Missouri., p95-97.

20. Sisson, S. and Grossman. J. D. (1966) The Anatomy of Domestic Animals, Edn 4 $4^{\text {th }}$, W. B. Saunders Co., Philadelphia and London.

21. Rathor, S. S. (1968) Clinical Aspect of the Functional Disorders of the Equine and Bovine Femoropatellar Articulation with some Remarks on its Biomechanics., Drukkerij Hoeijenbos, Utrecht.

22. Krishnamurthy, D., Tyagi, R. P. S., Ramakrishna, O. and Kharole, M. U. (1976) Histopathological observations on some of the structures involved in upward fixation of patella. Haryana Agricultural University Journal of Research. , 6(2): 140-143.

23. Gadgil, B. A. and Patel, M. R. (1977) Some observations on the chronic sub-luxation of patella in cattle. Indian Vet. J., 54: 989-994.

24. Gibbons, W. J. (1970) Stifle cramp. Mod. Vet. Pract., 51: 7576.

25. Krishnamurthy, D., Bhargava, A. K. and Tyagi, R. P. S. (1975) Roentgenographic observations on bovine stifles with impaired (subluxation) patellar functions. Indian Vet. J., 52(1): 64-68.

26. Dollar, J. A. W. (1895) Moller's Operative Veterinary Surgery, Edn $2^{\text {nd }}$., David Douglas, Edinburgh., p 601-605.

27. Liautard. A. (1906) A Treatise on Surgical Therapeautics of Domestic Animals., P. J. Cadet and J. Almy. Williams R. Jenkins, New York., p520-523. 
28. Smythe, R. H. (1934) Encyclopedia of Veterinary Medicine, Surgery and Obstetrics, Vol II., H. Wooldridge. Oxford University Press, London., p994-995.

29. O'connor, J. J. (1950) Dollar's Veterinary Surgery, Edn $4^{\text {th }}$., Bailliere, Tindall and Cox, London., p915-917.

30. Stanfield, G. (1967) Repair of upward fixation of patella in the bovine. Swest. Vet., 20: 233-234.

31. Mohanty, J. (1970) Upward fixation of patella in cattle. Proceedings of the Summer Institute in Veterinary Surgery, held at Hissar, Haryana, India.

32. Slatter, D. (2003) Small Animal Surgery, Edn $3^{\text {rd }}$, Vol II., Saunders, Philadelphia., p2123.

$* * * * * * * *$ 